\title{
SPIRITUALITAS PENDERITAAN AYUB MEMPERTANYAKAN EKSISTENSI ALLAH
}

\author{
Frets Keriapy \\ STAK Terpadu
}

\begin{abstract}
Job is a godly and righteous man of God in his era. God admires his faith highly because of that. A kind and good man like Job should have experienced the goodness and kindness of God for the rest of his life, but instead he experienced a great suffering and God allowed it happen. With suffering, people will wonder where is the justice of God? is God still be known as God with infinite love? if those attributes are still worth to be applied to God, then why would Job experienced that great suffering in his life as a godly and righteous man of God? Viewing it in ethical point of views of denying the existence of God, the writer is trying to answer in this writing that the suffering people have experienced it was not because God not existed, but instead, suffering was the plan of God to people. Suffering tested human spirituality.
\end{abstract}

\section{Key words: Spirituality, Suffering and Existence of God.}

\section{Pendahuluan}

Manusia adalah makhluk yang diciptakan oleh Allah secara istimewa. Istimewa karena proses Allah menciptakan manusia dengan cara berbeda dengan makhluk dan bahkan semua materi-materi yang ada di dunia ini ${ }^{1}$. Hal istimewa lainnya adalah manusia diciptakan serupa dan segambar dengan Allah. Martinus Theodorus Mawene mengatakan bahwa gambar dan rupa Allah harus dipahami menurut "patron yang dikehendaki Allah" atau menurut apa yang dibayangkan Allah". Di bagian lain dikatakan "Image Of God". ${ }^{23}$ Michael Horton mengatakan: " Created in God image and likeness for covenantal fellowship, we were made not for ourselves, but for God and for each other. No doubt Calvin recalled Augustine's opening in his Confesion, even expressed in the intimacy of prayer: "You have made us for yourself and our hearts find no peace until they rest in you". Oleh karena begitu istimewanya manusia dibandingkan dengan makhluk yang lain, menjadikan manusia sebagai wakil Allah di dunia ini dan diberikan mandat untuk berkuasa atas seluruh makhluk dan semua materi yang ada di dunia ini. Berkuasa bukan berarti seenaknya melakukan apa pun yang diinginkan oleh manusia. Allah memberikan sebuah larangan untuk tidak memakan buah yang berada di tengah-tengah, yakni pohon pengetahuan yang baik maupun yang jahat (Kej.2:17). Kesalahan terbesar yang dilakukan oleh manusia adalah tidak taat pada perintah Allah. Hal lain dikatakan oleh Eben N Timo karena keinginan manusia untuk keluar dari batas-batas yang telah Allah tetapkan dengan kata lain, mereka ingin sama seperti Allah sehingga manusia bertindak melampaui batas-batas tersebut. ${ }^{4}$ Dengan kejatuhan manusia, maka penderitaan mulai menggerogoti manusia. Penderitaan merupakan hukuman Allah atas ketidaktaatan/ketidaksetiaan kepada perintah Allah. Bukan hanya itu saja, bumi pun ikut menjadi rusak.

\footnotetext{
${ }^{1}$ Ada beberapa pandangan yang tidak menerima akan penciptaan Allah dari tidak ada menjadi ada (Creatio Ex Nihilo) yakni, alam semesta ini berasal dari substansi Allah, misalnya alam semesta ini berasal substansi Allah atau disebut emanasi dan pandangan yang serupa dengan itu adalah panteisme. Lihat Muriwali Yanto Matalu, Apologetika Kristen, (Malang: 2018), hal. 139.

${ }^{2}$ Martinus Theodorus Mawene, Perjanjian Lama dan Teologi Kontekstual, (Jakarta: 2012), hal. 184. Lihat juga Skripsi Frets Keriapy, Efektifitas Pelaksanaan Pola Pemuridan KAMBIUM Terhadap Keyakinan Keselamatan Anak Usia 13-18 Tahun, (Salatiga: 2017), hal. 1. hal. 45 .

${ }^{3}$ Michael Horton, Calvin On The Christian Life Glorifying and Enjoying God Forever, (Malang: 2017),
} 
Akhir-akhir ini kita mendengar akan bencana tsunami dan gempa yang terjadi di Palu dan Donggala yang memakan banyak korban dan juga banyak yang kehilangan orang yang disayangi. Tidak hanya itu saja, mereka pun harus kehilangan harta benda mereka dan menjadikan hidup mereka menderita. Bencana yang terjadi membuat manusia bertanya: Apakah Allah hanya berdiam diri melihat hal tersebut? Mengapa bencana harus terjadi? Apakah Allah tidak adil? bahkan orang yang baik (orang percaya) menerima hal yang serupa. Atau mungkin kita bertanya di mana letak kebaikan Allah? Hal serupa pun di alami oleh Ayub.

\section{Spiritualitas}

Kata Spirit dalam bahasa Inggris berasal dari kata spiritus (Latin), ruakh (Ibrani) dan pneuma (Yunani), yang di dalam Bahasa Indonesia disebut sebagai roh. Karena itu, kata spiritualitas sepadan dengan kata kerohanian. ${ }^{5}$ Spiritualitas bukanlah teologi akademis. Gregorius mendefinisikan spritualitas sebagai cara menempuh peziarahan menjadi menjadi sahabat Allah. ${ }^{6}$ Selanjutnya, spiritualitas Calvin adalah suatu usaha untuk mengungkapkan iman di tengah-tengah dunia yang penuh tantangan, dilema dan paradox, suatu cara hidup dan bertindak dalam kesatuan antara kerohanian individual dan kesalehan sosial. ${ }^{7}$

Melihat dari beberapa definisi spiritualitas di atas, maka dalam penulisan ini, makna spiritualitas yang dimaksud adalah hubungan intimacy manusia dengan Allah sekalipun sedang dalam penderitaan. Penderitaan yang mampu membuat manusia mempertanyakan teodise Allah dalam menghukum orang yang saleh. Dengan kata lain, mempertahankan iman kepada Allah sekalipun dalam situasi yang mencekam dan bahkan tetap bertindak jujur, saleh dan takut akan Allah seperti yang dilakukan oleh Ayub.

\section{Spiritualitas Penderitaan Ayub}

Dikatakan di dalam Ayub 1:1 bahwa Ayub ${ }^{8}$ adalah orang saleh dan jujur bahkan ia takut akan Allah dan menjauhi kejahatan. Mungkin kita akan berkata bahwa orang sebaik Ayub akan menerima kebaikan Allah seumur hidupnya. Kita juga bisa berkata bahwa orang seperti Ayub tidak akan menerima hal yang buruk dalam hidupnya. Namun yang terjadi berbeda. Di pasal pertamadan kedua diceritakan oleh penulis kitab Ayub bahwa iblis menghadap Allah dan meminta agar hal-hal buruk menimpa Ayub supaya ia tidak lagi percaya kepada Tuhan.

${ }^{5}$ Muriwali Yanto Matalu, Keagungan dan Keindahan Rohani, (Malang:2017), hal. 11.

${ }^{6}$ J. B. Banawiratma, et.al, Spiritualitas Dari Berbagai Tradisi, (Yogyakarta: 2017), hal.13.

${ }^{7}$ Ibid. hal, 13

${ }^{8}$ Nama Ayub berarti: „Di manakah ayah (ilahi)? Dan, dalam bentuk ini, mengungkapkan permintaan untuk pertolongan Allah. Bagi telinga Ibrani, kata 'Ôyeb ,musuh juga bergema dalam nama' $i y y \hat{O} b$ sehinga Ayub dapat dipahami sebagai („musuh Allah") atau orang yang membenci (Allah)". Qur"an mengasosiasikan nama tersebut (Arab: „Ayub) dengan kata „awab (,pertobatan/penyesalan), jadi Ayub adalah teladan pertobatan (Sura 38:44). Baik mengasosiasikan dengan kata Ibrani 'Ôyeb(,musuh") maupun dengan kata Arab „awab (,penyesalan") bukanlah turunan-turunan filologis yang autentik, melainkan mereka membuka asosiasi-asosiasi pemahaman kitab yang memang dimaksudkan oleh para rabi paling awal dari tradisi Ayub. (Lihat: Markus Witte, et.al, Purwa Pustaka Eksplorasi Ke Dalam Kitab-Kitab Perjanjian Lama dan Deuterokanonika, (Jakarta: 2017), hal. 649 
Pada pasal 1 semua harta benda Ayub habis lenyap, anak-anaknya mati. Pasal 2 kita melihat iblis kembali menghadap Allah agar supaya mengijinkannya untuk menjamah tubuhnya. Allah mengijinkannya dan iblispun melakukan demikian. Penderitaan Ayub bertambah dengan penyakit kusta yang dialaminya. Penyakit mematikan tersebut menimpah Ayub dan bahkan istrinya pun mengatakan bahwa lebih baik Ayub mengutuki TUHAN dan matilah! (Ayub 2:9). Bencana membuat manusia berani menyalahkan Tuhan dan bahkan mengutukinya. Bencana membuat manusia mulai berpikir bahwa mungkin Tuhan sudah mati (seperti orang gila yang berlari-lari di pasar sambil berkata Tuhan sudah mati! (pandangan Nietzche)).

Romo Magnis Suseno dalam bukunya "Menalar Tuhan" mengatakan bahwa dengan adanya kejahatan dan penderitaan kelihatan sedemikian bertentangan dengan eksistensi Allah yang Mahatahu, Mahakuasa dan Mahabaik sehingga Allah seakan-akan perlu dibenarkan. Manusia seakanakan mengajukan protes: Bagaimana Engkau, Allah yang adil dan mahabaik, dapat mengizinkan keadaan seperti ini berlangsung? Protes itu barangkali dengan paling tajam diteriakkan oleh Ayub: "Aku telah bosan hidup, aku hendak melampiaskan keluhanku, Aku hendak berbicara dalam kepahitan jiwaku... Aku berseru minta tolong kepadaMu, tetapi Engkau tidak menjawab; aku berdiri menanti, tetapi Engkau tidak menghiraukan aku... Anak panah dari Yang Mahakuasa tertanjap pada tubuhku... Semuanya itu sama saja, itulah sebabnya aku berkata: yang tidak bersalah dan yang bersalah kedua-duanya dibinasakanNya" (Ayub 10:1; 30:28; 6:4; 9:22). Tak dapat diragukan; penderitaan orang yang tidak bersalah adalah scandalum, batu sandungan paling gawat, bagi orang yang mau percaya kepada Allah. ${ }^{9}$ Secara sekilas kita mendengar dan melihat teriakan Ayub membuat kita bertanya akan hal-hal yang sudah saya jelaskan di atas. Bagaimana mana bisa Allah yang Mahabaik, Mahakuasa dan Mahaadil membiarkan orang yang jujur dan dan bahkan takut akan Allah menerima penderitaan dengan begitu dahsyat.

Banyak orang yang melihat penderitaan sebagai sesuatu yang menyedihkan dan merupakan upah dari dosa yang telah dilakukan. Seperti sahabat-sahabat dari pada Ayub yang datang mengunjunginya dan berkata mungkin Ayub telah melakukan hal yang salah (Ayub telah berdosa) sehingga ia mengalami penderitaan (Ayub 4-5). Istri Ayub sendiripun menyalahkan TUHAN atas musibah yang menimpah Ayub (Ayub 2:9). Sementara sebagian orang lain memahami bentuk penderitaan merupakan sebentuk ujian bagi orang benar. Antara kedua penafsiran ini terdapat penafsiran atas penderitaan sebagai sarana-sarana pengajaran dari Allah suatu penafsiran yang khusus disajikan oleh Elihu ${ }^{10}$ (Lihat Ayub 32:1-22). Oleh karena itu, cara pandang kita terhadap penderitaan atau terhadap sesuatu hal yang sedang dialami sangat memengaruhi cara pandang kita akan Allah.

Setiap penderitaan yang dialami oleh Ayub merupakan bagian dari pada kehendak Allah. Hery Susanto mengatakan bahwa cara Ayub meresponi penderitaan yang dialaminya menunjukkan sikap seorang manusia yang memiliki kesadaran bahwa apa yang terjadi bukan karena kesalahan manusia tetapi rancangan Allah. ${ }^{11}$ Selanjutnya John Calvin mengatakan bahwa the special providence is concerned more particularly with man, and with the constant intervention of God in the life of man. ${ }^{12}$ Setiap hal yang terjadi dalam hidup manusia, baik suka maupun duka, semuanya berada dalam

${ }^{9}$ Franz Magnis Suseno, Menalar Tuhan, (Yogyakarta: 2017), hal. 216.

${ }^{10}$ Markus Witte, et.al, Op.Cit, hal. 665.

${ }^{11}$ Hery Susanto, The Awareness Of God (Kesadaran Akan Allah Berdasar Perspektif Kitab Ayub), (Salatiga: 2014), hal. 31

${ }^{12}$ Francois Wendel, Calvin The Origins And Developement Of His Religious Thought, (New York: 1963), hal. 179. 
kehendak Allah. Allah tidak hanya menciptakan dunia ini beserta isinya (termasuk manusia di dalamnya) lalu membiarkannya begitu saja. Sebaliknya, Allah turut bekerja dalam seagala situasi yang terjadi bahkan sampai pada saat ini.

Mempercayai rancangan Allah berarti mempercayai akan segala hal yang terjadi berada di bawah kendali-Nya. Penderitaan besar yang dialami oleh manusia sekali pun tidak akan menggoyahkan iman manusia akan Allah. Iman yang teguh membuat manusia mempercayai bahwa Allah tetap hadir dalam situasi yang sulit bahkan dalam keadaan menderita.

filsul-filsul eksistensialis dan ateis ${ }^{13}$ seperti Jean-Paul Sartre mengatakan bahwa manusia adalah makhluk bebas oleh karena itu, manusia harus lepas dari segala hal yang dapat mengikatnya termasuk di dalamnya TUHAN ${ }^{1415}$. Friedrich Nietzsche mangatakan bahwa Tuhan sudah mati dan yang mematikan Tuhan adalah manusia sendiri dengan berbagai kejahatan yang telah terjadi. ${ }^{16}$ Ludwig Feuerbach mengatakan bahwa agama adalah hasil proyeksi manusia ${ }^{17}$. Dengan kata lain, Tuhan merupakan hasil daripada pemikiran manusia. Nah, jika seseorang mengalami suatu bencana atau penderitaan dan memiliki cara pandang yang salah tentang Allah, maka mereka dapat terjerumus dalam berbagai pandangan ini.

Santo Augustinus mencoba membuktikan adanya Allah dengan menekankan bahwa manusia mampu mengerti kebenaran. ${ }^{18}$ Selanjutnya Thomas Aquinas memberikan lima jalan (Quinque viae) untuk membuktikan bahwa Allah ada. Lima jalan tersebut adalah: ${ }^{19}$ Jalan yang pertama dan yang paling nyata diambil dari perubahan, Jalan kedua diambil dari konsep „penyebab pelaksana", jalan ketiga dari „yang mungkin" dan ,yang harus “e, Jalan keempat diambil dari tingkat-tingkat yang terdapat dalam benda-benda, jalan kelima diambil dari pengaturan dunia.

Anselmus dari Canterburry dalam tulisannya yang berjudulProslogion, ia mencoba membuktikan keberadaan (eksistensi) Allah secara ontologis. Allah adalah lebih dari yang dapat kita pikirkan. ${ }^{20}$ Selanjutnya Yewangoe, menyederhanakan hal ini dengan berkata bahwa "Kalau anda memikirkan sesuatu dalam pikiran anda, mestinya obyek yang dipikirkan itu ada yang melampaui

\footnotetext{
${ }^{13}$ Ateisme dogmatis adalah golongan orang-orang ateis yang percaya secara dogma bahwa Allah tidak ada. (Lihat: Muriwali Yanto Matalu, Dogmatika Kristen Dari Perspektif Reformed (last edition), (Malang: 2017), hal. 187.

${ }^{14}$ Franz Magnis Suseno, Op.Cit, hal. 93.

${ }^{15}$ Jean Paul Sartre says: Man is responsible for what he is... We are alone, without excuses. This is what I mean when I say that man is condemned to be free. (Lihat: Setyo Wibowo, et.al. Filsafat Eksistensialisme Jean-Paul Sartre, (Yogyakarta: 2011), hal. 49.

${ }^{16}$ Nietzsche tidak mengatakan bahwa "aku yang membunuh Tuhan", melainkan "kita telah membunuhNya" (Lihat: Setyo Wibowo, Gaya Filsafat Nietzsche, (Yogyakarta: 2017), hal. 331.

${ }^{17}$ Franz Magnis Suseno, Op.Cit, hal. 66

${ }^{18}$ Harry Hamersma, Persoalan Ketuhanan Dalam Wacana Filsafat, (Yogyakarta: 2014), hal.45.

${ }^{19}$ Ibid, hal. 48-49

${ }^{20}$ A.A. Yewangoe, Allah Mengizinkan Manusia Mengalami Diri-Nya, (Jakarta: 2018), hal.3.
} 
pemikiran itu sendiri. Kalau obyek itu tidak ada, mustahillah memikirkan yang dapat dipikirkan. Begitu Allah ada dalam pikiran kita, kita berpikir mengenai Allah. ${ }^{21}$

Mengatakan bahwa Allah tidak ada sama hal dengan mengatakan bahwa tidak ada lagi kebenaran di dunia ini. Mangatakan bahwa penderitaan adalah bukti akan ketidakadaan Allah merupakan kesimpulan yang terlalu terburu-buru. Kejahatan tidak pernah menentukan ada dan tidak adanya Allah. Hamersma mengatakan bahwa suatu teodise tidak pernah akan berhasil, karena "pembenaran Allah terhadap akal budi manusia" tidaklah mungkin. Allah bukan terdakwa, manusia bukan hakim terhadap Allah, dan teodise bukanlah pengacara. ${ }^{22}$ Selanjutnya Hamersma mengutip pernyaatan Jaspers bahwa teodise tidak membuktikan bahwa Allah tidak ada, melainkan bahwa teodise adalah tidak mungkin, dan hal itu memang sudah diketahui sejak lama. ${ }^{23}$ Sebaliknya, penderitaan yang terjadi membuat iman kepada Allah semakin kuat.

John Calvin mengatakan bahwa setiap masalah yang kita hadapi seharusnya membuat kita tetap teguh percaya kepada Tuhan. Semua hal yang terjadi dalam hidup manusia Tuhan tidak pernah berdiam diri. Setiap pencobaan yang kita alami tidak akan pernah melebihi kekuatan kita sendiri (1 Kor. 10:13). Seperti yang doa dari pada Augustinus bahwa "You have made us for yourself and our hearts find no peace until they find rest in You." Saya tidak bisa bayangkan bagaimana jadinya dunia ini jika Pencipta dunia (TUHAN) ini mati atau tidak eksis. seperti paham beberapa filsuf eksistensialis di atas.

\section{Kesimpulan:}

Dari beberapa hal yang telah saya jelaskan di atas, dapat dilihat bahwa penderitaan yang terjadi/menimpah manusia merupakan rancangan Allah terhadap manusia. Allah mengijinkan hal itu terjadi supaya manusia terus mempercayai akan Allah. Tidak hanya itu, dalam keadaan menderita sekalipun, manusia terus memiliki iman yang teguh bahwa Allah telah mempersiapkan rancangan yang besar di kemudian hari.

Cara kita memandang penderitaan yang sedang dialami dapat memengaruhi cara pandang kita terhadap Allah yang hidup. Penderitaan yang kita alami tidak lepas daripada campur tangan Allah. Kejahatan bahkan penderitaan tidak dapat membuktikan akan ketidakberadaan Allah. Sebaliknya, dalam penderitaan yang dialami manusia Allah justru hadir dan terus melindungi manusia.

Saat iblis datang kepada Allah untuk memberikan penawaran agar supaya membuat Ayub menderita, ada perkataan yang Allah keluarkan kepada iblis, yakni "hanya saja jangan engkau mengulurkan tanganmu terhadap dirinya." (Ayub 1:12) dan "sayangkan nyawanya" (Ayub 2:6), ini membuktikan bahwa Tuhan selalu melindungi orang-orang yang percaya dan takut akan Allah sekalipun dalam penderitaan. Tuhan mengijinkan penderitaan kepada manusia bukan berarti Tuhan meninggalkan manusia. Penderitaan yang dialami manusia bukan berarti Tuhan tidak hadir dalam setiap penderitaan yang dialami manusia. Di balik penderitaan yang dialami oleh manusia, selalu ada berkat. Jika kita membaca di akhir kisah Ayub, Tuhan memberkati Ayub berlipat-lipat dari apa yang pernah Ayub peroleh sebelumnya. Spiritualitas Ayub teruji sekali pun dalam berbagai penderitaan. Spiritualitas Ayub teruji sekalipun kehilangan harta benda dan bahkan orang-orang yang dia kasihi. Spiritualitas Ayub teruji sekali pun berada dalam situasi yang paradox di mana saat keadaan yang

\footnotetext{
${ }^{21}$ Ibid.

${ }^{22}$ Harry Hamersma, op. Cit, hal. 99

${ }^{23}$ Ibid.
} 
sulit, tidak meninggalkan Allah dan bahkan tidakmengutuki Allah seperti yang dikatakan oleh istrinya.

Untuk menutup tulisan saya, saya ingin mengutip satu pernyataan radikal yang dikatakan oleh Ayub saat dirinya mengalami penyakit kusta dan bahkan istrinya sendiri pun meminta Ayub mengutuki Allah: "Maka berkatalah istrinya kepadanya: Masih bertekunkah engkau dalam kesalehanmu? kutukilah Allahmu dan matilah! Tetapi jawab Ayub kepadanya "Engkau berbicara seperti perempuan gila! APAKAH KITA MAU MENERIMA YANG BAIK DARI ALLAH, TETAPI TIDAK MAU MENERIMA YANG BURUK? Dalam kesemuanya itu Ayub tidak berbuat dosa dengan bibirnya. (Ayub 2:9-10). 


\section{Dafftar Pustaka:}

\section{Sumber Buku:}

Banawiratma, J.B. et.al. 2017. Spiritualitas Dari Berbagai Tradisi. Yogyakarta: Kanisius

Hamersma, Harry. 2014. Persoalan Ketuhanan Dalam Wacana Filsafat. Yogyakarta: Kanisius

Horton, Michael. 2017. Calvin On The Christian Life. Malang: SAAT

Matalu, Yanto Muriwali. 2018. Apologetika Kristen. Malang: GKKR

Matalu, Yanto Muriwali. 2017. Dogmatika Kristen Dari Perspektif Reformed (Last Edition), Malang: GKKR

Matalu, Muriwali Yanto. 2017. Keagungan Dan Keindahan Rohani. Malang: GKKR

Mawene, Theodorus Martinus. 2012. Perjanjian Lama dan Teologi Kontekstual. Jakarta: BPK Gunung Mulia

Nuban, Timo I. Ebenhaizer. 2016. Allah Menahan Diri, Tetapi Pantang Berdiam Diri.Jakarta: BPK Gunung Mulia

Susanto, Hery. 2014. The Awareness Of God(Kesadaran Akan Allah Berdasar Perspektif Kitab Ayub). Salatiga: Tisara Grafika

Suseno, Magnis Franz. 2017. Menalar Tuhan. Yogyakarta: Kanisius

Wendel, Francois. 1963. Calvin The Origins And Developement Of His Religious Thought. New York: Harper \& Row, Publisher.

Witte, Markus, et.al. 2017. Purwa Pustaka Eksplorasi Ke Dalam Kitab-Kitab Perjanjian Lama Dan Deuterokanonika. Jakarta: BPK Gunung Mulia

Wibowo, Setyo. A.2017. Gaya Filsafat Niezsche. Yogyakarta: Kanisius

Wibowo, Setyo A. et.al. 2017. Filsafat Eksistensialisme Jean Paul Sartre. Yogyakarta: Kanisius

Yewangoe, A.A. 2018. Allah Mengizinkan Manusia Mengalami Dirinya. Jakarta: BPK Gunung Mulia

\section{Sumber Lain:}

Keriapy Frets. 2017. Efektifitas Pola Pemuridan KAMBIUM Terhadap Keyakinan Keselamatan Anak Usia 13-18 Tahun (Skripsi). 